\title{
A common symptom with an uncommon diagnosis
}

\author{
Prabu Velayutham, Prem Davis ${ }^{*}$, Nishanth Savery and Ramprasath Vaigundavasan
}

\begin{abstract}
Background: Nasopharyngeal carcinoma is one of the uncommon tumours and the most difficult tumour to diagnose at an earlier stage due to the clandestine and deceptive nature. The incidence is more common in men with a peak incidence of 50 to 60 years. The suspicion of tumour at the earliest stage is very helpful in reducing morbidity and mortality.

Case presentation: A 45-year-old female presented with right hemi cranial headache for 2years without any comorbidities for that she consulted many hospitals and got symptomatic and empherical treatment in which her symptoms resolved temporarily and recurred. We did diagnostic nasal endoscopy and found a smooth globular mass in the right nasopharynx with contrast enhanced computerised tomography mass extending into the muscle plane which was found with the confirmation of diagnosis as undifferentiated nasopharyngeal carcinoma by histopathological examination and treated accordingly.

Conclusion: Although the diagnosis of the nasopharyngeal carcinoma in the earlier stage is difficult, it is an imperative one because the prognosis depends upon the stage of the disease in which it has been diagnosed. The clinicians always should have a suspicion of the rare disease for a day-to-day unresolved symptom, because the earlier diagnosis and appropriate management helps in the prevention of the life-threatening complications of any disease.
\end{abstract}

Keywords: Nasopharyngeal carcinoma, Undifferentiated carcinoma, Headache, Medial pterygoid plate

\section{Background}

The Nasopharyngeal Carcinoma (NPC) is an uncommon tumour that arises from the epithelial lining of the nasopharynx [1]. In 1921, Regaud and Schmincke described the NPC as a separate entity [1]. The incidence of nasopharyngeal carcinoma worldwide is 1.2 per lakh population [2]. However, the incidence of NPC in India is not known due to underreporting of cases. The NPC is more commonly seen among Chinese, Southeast Asians, North Africans and native people of the Arctic region [3]. The incidence is more common in men than women with a ratio of 2 to $3: 1$. The peak incidence of NPC is the age group of 50 to 60 years in which the elderly are at increased risk of relapse with a lower survival rate [2].

\footnotetext{
* Correspondence: premdavis93@gmail.com

Department of ENT, Sri Venkateshwaraa Medical College, Hospital and Research Centre, Ariyur, Puducherry 605012, India
}

We report a case of a 45-year-old female diagnosed as stage III NPC with complaints of right hemi cranial headache for 2 years without any ear, nose, throat, neck and neurological symptoms.

\section{Case presentation}

A 45-year-old female belonging to low socio-economic status presented to our hospital with a history of headache for the past 2 years. The headache is insidious onset, continuous in course, dull aching type of pain, and it is localised to the bilateral parietal region. No aggravating factors and partially relieved on medications. The headache is not associated with nausea, vomiting, visual disturbance, neck stiffness, fever, rash, weight loss, sleep disturbance and neurological deficit. Before coming to our hospital, she consulted many hospitals for her complaints and got symptomatic and empherical treatment
Springer Open

(c) The Author(s). 2021 Open Access This article is licensed under a Creative Commons Attribution 4.0 International License, which permits use, sharing, adaptation, distribution and reproduction in any medium or format, as long as you give appropriate credit to the original author(s) and the source, provide a link to the Creative Commons licence, and indicate if changes were made. The images or other third party material in this article are included in the article's Creative Commons licence, unless indicated otherwise in a credit line to the material. If material is not included in the article's Creative Commons licence and your intended use is not permitted by statutory regulation or exceeds the permitted use, you will need to obtain permission directly from the copyright holder. To view a copy of this licence, visit http://creativecommons.org/licenses/by/4.0/. 
for sinusitis in which her symptoms resolved temporarily and recurred.

And there was no history of ear pain, ear discharge, hard of hearing, tinnitus and vertigo. There was no history of nasal obstruction, nasal discharge, epistasis, smell disturbance and facial puffiness. And there is no history suggestive of throat diseases such as restriction of mouth opening, difficulty or pain during swallowing, throat pain, voice change, frequent clearing of throat, breathing difficulty, or neck swelling or pain.

In the general-physical examination, the patient had mild pallor with stable vitals. Systemic examination was found to be normal. On an ENT examination, we found a dull and retracted tympanic membrane on the right ear with normal features found on the left side. Examination of the nose was normal. Then we proceeded with the diagnostic endoscopic examination, in that we found a smooth globular mass of about $2 \mathrm{~cm} \times 1 \mathrm{~cm}$ side occupying the right side of the nasopharynx obstructing the eustachian tube opening as shown in Fig. 1. The other side of the nasopharynx was found to be normal.

Throat examination was found to be normal. Her investigations revealed anaemia with the mild microcytic hypochromic picture; other parameters of complete blood count were normal. Contrast enhanced computerised tomography (CECT) shows ill-defined hypodense mass lesions in the right lateral wall of the nasopharynx as shown in Fig. 2. An enlarged rounded lymph node of size $1.5 \mathrm{~cm} \times 1.2 \mathrm{~cm} \times 2 \mathrm{~cm}$ is noted on the right side at the level of $\mathrm{V}$ which was not clinically palpable as shown in Fig. 3. Nasopharyngeal biopsy was taken under general anaesthesia and histopathological examination feature suggestive of the undifferentiated type of nasopharyngeal carcinoma as shown in Fig. 4. And the patient was categorised as T3M1N0- stage III based on American Joint

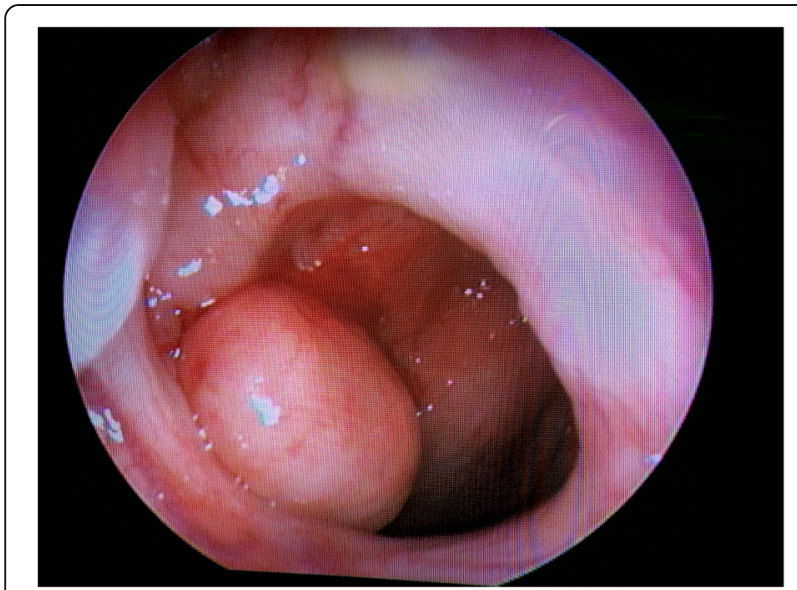

Fig. $1 \mathrm{~A}$ smooth globular mass of about $2 \mathrm{~cm} \times 1 \mathrm{~cm}$ side occupying the right side of the nasopharynx obstructing the eustachian tube opening
Committee on cancer 2016. The patient was being treated with a cisplatin at $160 \mathrm{mg}$ followed $\left(100 \mathrm{mg} / \mathrm{m}^{2}\right)$ every 3 weeks for 3 cycles from the first day radiotherapy at the rate of 5 daily fractions delivered each week for 6 to 7 weeks. And the patient was advised to follow up after a course of chemotherapy.

\section{Discussion}

In the year 2005, the World Health Organization classified NPC into three histological subtypes: keratinising squamous cell carcinoma; nonkeratinising carcinoma, which can be further divided into differentiated and undifferentiated subtypes; and basaloid squamous cell carcinoma. Among the most common type of NPC is the undifferentiated nonkeratinising type and which is strongly associated with Epstein-Barr virus infection [4]. Other risk factors such as family history, consumption of salt-preserved fish, Chinese herbal drugs, lack of intake of fresh fruits and vegetables and tobacco and alcohol consumption also lead to the development of the disease [1]. The lateral wall of the nasopharynx especially the fossa of Rosenmuller is the most common site of origin of NPC, followed by the superior posterior wall [5]. The most common presentation of NPC is cervical lymphadenopathy. Lateral retropharyngeal lymph nodes are the first to be involved, but the first palpable lymph node is jugulodigastric lymph node. Pain, trismus otitis media, nasal regurgitation, hearing loss, aural block due to eustachian tube blockage and cranial nerve palsies are the common symptoms due to primary tumour. Larger growth may produce symptoms like nasal obstruction or bleeding and a "nasal twang". The metastasis of the tumour will lead to bone pain and organ dysfunction in later stages [1]. It is very interesting to see that, in our case, no such risk factors or clinical features were found and the patient presented with headache as the only complaint. The diagnosis of the NPC was mainly based on history, clinical examination, diagnostic nasal endoscopy to look for the nasopharyngeal mass followed by computerised tomography $(\mathrm{CT})$ and magnetic resonance imaging to evaluate the extent of the lesion, and chest $\mathrm{x}$ ray and bone scintigraphy to rule of the distant metastasis of the tumour [1]. The histopathological examination is the gold standard in the diagnosis of NPC [6]. In our case, although the history and clinical examination did not give a clue towards the correct pathway. The diagnostic nasal endoscopy shows a globular smooth mass in contrast to the NPC of the nasopharynx with an ulcerated surface and a raised nodule [7].

The CECT of our patient shows the extent of lesions towards the parapharyngeal space with loss of muscle plane and the involvement of the medial pterygoid. It is very interesting to see here that although this much involvement has been seen in $\mathrm{CT}$, the patient did not give 


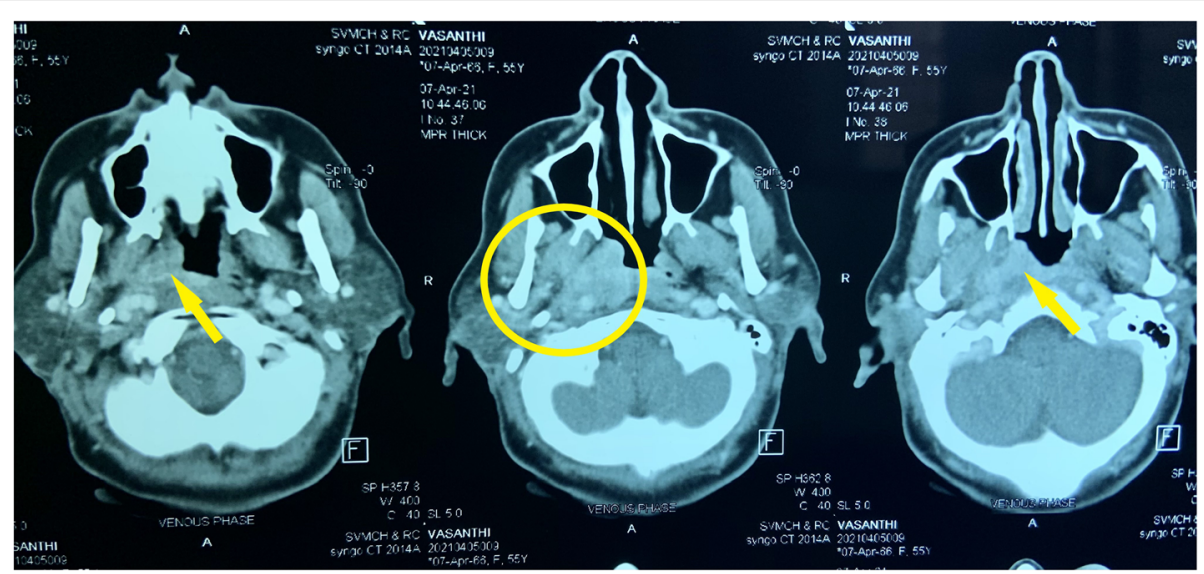

Fig. 2 Contrast enhanced computerised tomography shows ill-defined hypodense mass lesions in the right lateral wall of nasopharynx extending to midline causing nasopharyngeal airway narrowing. The lesion involving the fossa of Rosenmuller, torus tubaris with involvement of eustachian tube. It is also abutting lateral pterygoid muscle with loss of fat plane; inferiorly it is entering the parapharyngeal space in right side. Slight rarefaction of medial pterygoid process

any complaints of restriction of mouth opening, neck pain and difficulty in swallowing. And from this, we are able to correlate the cause of headache as the medial pterygoid plate involvement. The erosion of the pterygoid plates leads to chronic inflammatory changes in the site of attachment of the pterygoid muscles; these chronic inflammatory changes involve the branches of mandibular division of trigeminal nerve, which explains the cause of headache in this cas e[8]. In our case, histopathological examination helps in confirming the diagnosis as a gold

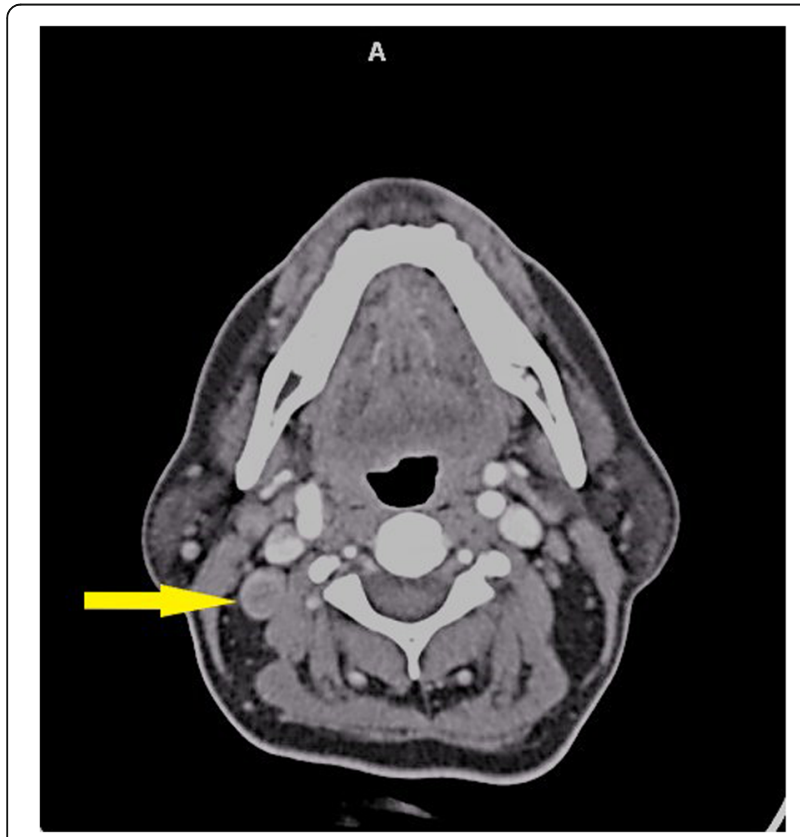

Fig. 3 Contrast enhanced computerised tomography shows an enlarged rounded lymph node of size $1.5 \mathrm{~cm} \times 1.2 \mathrm{~cm} \times 2 \mathrm{~cm}$ is noted on the right side at the level of $\mathrm{V}$ standard one. After the investigations, the staging of the cancer was made based on American Joint Committee on Cancer (AJCC) staging system for nasopharyngeal carcinoma 8th edition [9]. The AJCC staging system is useful in the selection of the treatment modality for the NPC. For the treatment of early-stage of tumour (stages I and II), radiotherapy with a dose of 66-72 Gray (Gy) to the primary tumour and affected lymph node area and 50 Gy to the uninvolved neck is sufficient [10]. For the treatment of localised advanced disease (stages III and IV) concurrent chemoradiation is the standard treatment (with cisplatin at $100 \mathrm{mg} / \mathrm{m}^{2}$ every 3 weeks for 3 cycles). But the distant

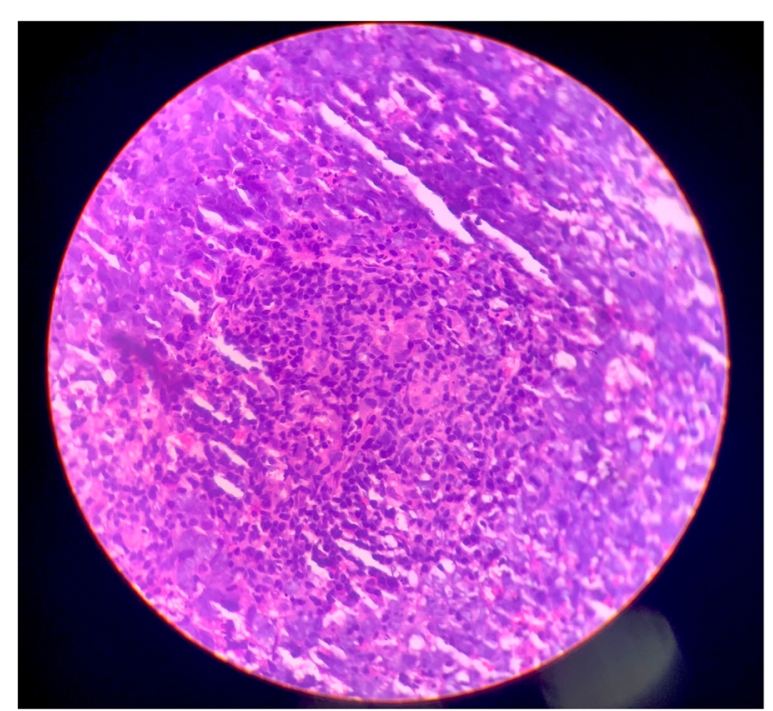

Fig. 4 HPE shows tumour composed of nests and sheets of atypical cells which are surrounding by dense lymphoplasmacytic infiltrate. Tumour cells are large with moderate pleomorphism, vesicular nucleus with prominent nucleoli and scant cytoplasm 
metastasis is the main cause for the treatment failure [11, 12]. The General Physicians initially managed as chronic rhinosinusitis and later as cephalon-cervical musculoskeletal pain after the CT-paranasal sinus was found to be normal. This leads to a significant delay in the diagnosis and treatment which has caused the spread of the tumour to the muscle plane and the parapharyngeal space with the erosion of the medial pterygoid which in turn leads to the progression of the disease to stage III and the patient was started on chemoradiation.

\section{Conclusion}

The NPC is a silent malignancy due to a multitude of presentation. Although the diagnosis in the early stage is difficult due to the presence of non-specific symptoms, the diagnosis became an imperative one, because of the prognostic factor which mainly depends on the stage, extent, time of diagnosis and extent of disease. The present article highlights that the clinician should have a suspicion of an uncommon serious disease for even a common day to day symptoms if they are refractory, recurrent or of chronic duration for the early diagnosis and treatment.

\section{Abbreviations}

NPC: Nasopharyngeal carcinoma; CECT: Contrast enhanced computerised tomography; CT: Computerised tomography; Gy: Gray

\section{Acknowledgements}

None

\section{Authors' contributions}

All authors read and approved the final manuscript. PV carried out the conception and literature review, analysed and interpreted the patient's data and diagnosed the patient. PD carried out conception, writing, and editing the manuscript for submission. NS contributed in the laboratory work and critical revision of the draft and shared in the final manuscript writing. RV contributed in reviewing the manuscript and diagnosed the patient.

\section{Funding}

No funding

\section{Availability of data and materials}

Available

\section{Declarations}

Ethics approval and consent to participate

Not applicable

\section{Consent for publication}

Written informed consent for publication of his clinical details and/or clinical images was obtained from the patient.

\section{Competing interests}

No conflict of interest.

Received: 22 June 2021 Accepted: 27 August 2021

Published online: 19 September 2021

\section{References}

1. Brennan B (2006) Nasopharyngeal carcinoma. Orphanet J Rare Dis 1(1):23. https://doi.org/10.1186/1750-1172-1-23
2. Salehiniya $\mathrm{H}$, Mohammadian M, Mohammadian-Hafshejani $\mathrm{A}$, Mahadavifar $\mathrm{N}$ (2018) Nasopharyngeal cancer in the world: epidemiology, incidence, mortality and risk factors. World Cancer Res J 5(1):e1046

3. Wei WI, Sham JS (2005) Nasopharyngeal carcinoma. Lancet 365(9476):20412054. https://doi.org/10.1016/S0140-6736(05)66698-6

4. Cui C, Lio L, Ma J, Liang S, Tian L, Tang L (2009) Trigeminal nerve palsy in nasopharyngeal carcinoma: correlation between clinical findings and magnetic resonance imaging. Head Neck 31(6):822-828. https://doi.org/10.1 002/hed.21101

5. Kamio Y, Sakai N, Takahashi G, Baba S (2014) et al, Nasopharyngeal carcinoma presenting with rapidly progressive severe visual disturbance: a case report. J Med Case Rep 8(1):361. https://doi.org/10.1186/1752-1947-8-361

6. Suwondo S, Surarso B, Kristyono I (2019) Biopsy examination validity based on narrow band imaging guidance of nasopharyngeal varcinoma suspected patients. Indian J Otolaryngol Head Neck Surg 71(Suppl 1):395-399. https:// doi.org/10.1007/s12070-018-1324-5

7. Thompson LD (2007) Update on nasopharyngeal carcinoma. Head Neck pathol 1(1):81-86

8. Marglani O, Shaikh AM (2015) Allergic fungalsinusitis eroding the pterygoid plates: a rare case series. Braz J Otorhinolaryngol 81(1):109-112. https://doi. org/10.1016/j.bjorl.2014.05.028

9. Chen YP, Chan ATC, Le QT, Blanchard P, Sun Y, Ma J (2019) Nasopharyngeal carcinoma. Lancet. 394(10192):64-80. https://doi.org/10.1016/S0140-6736(1 9)30956-0 Epub 2019 Jun 6. PMID: 31178151

10. Lee AW, Ng WT, Chan LL, Hung WM, Chan CC, Sze HC et al (2014) Evolution of treatment for nasopharyngeal cancer-success and setback in the intensity-modulated radiotherapy era. Radiother Oncol 110(3):377-384. https://doi.org/10.1016/j.radonc.2014.02.003

11. Ribassin-Majed L, Marguet S, Lee AW, Ng WT, Ma J, Chan ATC et al (2017) What is the best treatment of locally advanced nasopharyngeal carcinoma? An individual patient data network meta-analysis. J Clin Oncol 35(5):498505. https://doi.org/10.1200/JCO.2016.67.4119

12. Lv JW, Qi ZY, Zhou GQ, He XJ, Chen YP, Mao YP, Chen L, Tang LL, Li WF, Lin $\mathrm{AH}$, Ma J, Sun $Y$ (2018) Optimal cumulative cisplatin dose in nasopharyngeal carcinoma patients receiving additional induction chemotherapy. Cancer Sci 109(3):751-763. https://doi.org/10.1111/cas.13474

\section{Publisher's Note}

Springer Nature remains neutral with regard to jurisdictional claims in published maps and institutional affiliations.

\section{Submit your manuscript to a SpringerOpen ${ }^{\oplus}$ journal and benefit from:}

- Convenient online submission

- Rigorous peer review

- Open access: articles freely available online

High visibility within the field

Retaining the copyright to your article

Submit your next manuscript at $\boldsymbol{\nabla}$ springeropen.com 